\title{
Character Education in Nursing
}

\author{
Jeong hye Park \\ Dept. of Nursing, Gyeongnam National University of Science and Technology, Korea \\ masternur@naver.com
}

\begin{abstract}
The purpose of this study was to investigate the levels of nurses' character in clinical settings for developing the character education program in nursing. Data of 683 nurses in clinical settings were secondarily analyzed using t-test, one-way ANOVA and Scheffé test with IBM SPSS Statistics 20.0 program. The mean score of nurses' characters was $3.83 \pm 0.36$ of five. The factors of the highest score were integrity, reliability and etiquette. And the ones of the lowest score were composure, enthusiasm and civility. The scores of general nurses, under master's course and less than 10 years employment groups were lower than those of the other groups in teamwork. The results of this study suggest nurses' and students' character education program for better care in clinical settings.
\end{abstract}

Keywords: Character, Education, Policy, Nursing, Nurse

\section{Introduction}

Character refers to an individual's personality, ways of thinking, attitude, and behavioral characteristics [1]. The South Korean educational system revolves around university admission and a social context where students tend to make the sole purpose of their career path, employment [2][3]. In this context, it is inconceivable that only those students who possess the basic level of the character and talent required for nursing, and have sufficiently considered their aptitude and potential, or who possess a high career self-efficacy toward nursing, choose to study nursing. In addition, even in university environments that focus on academic achievement, students are typically studying with a narrow focus on acquiring work experience and employment. Thus, it is difficult for students to form healthy interpersonal relationships, or to cultivate their character to meet the society's expectations of university graduates [4].

Although recent research has suggested nursing professors perceived that the overall maturity of nursing students' character is intermediate, scoring $3.57 \pm 0.74$ out of 5 [5], much effort is still required in considering the importance of character in nursing. In clinical settings, patients suggest that what they perceive as a good nurse is friendly, sincere, caring, understanding, trustworthy, and virtuous [6][7][8]. Patients also expect nurses to provide help willingly, with sincere attitudes and polite behaviors [9][10]. However, most nurses fail to meet the expectations of patients in terms of their character [9][10]; in particular, many nurses fail to treat their patients in a fair manner, to respond immediately to patients' requests, and to acquire sufficient professional knowledge [10]. Therefore, in order to increase the quality of nursing and to provide satisfactory nursing services to patients, it is essential to investigate

Article history:

Received (July 21, 2016), Review Result (September 09, 2016), Accepted (October 28, 2016) 
the maturity of practicing nurses' characters, to find appropriate strategies to foster their character, which is arguably a prerequisite for quality care and performance.

\section{Methods}

\subsection{Participants and data collection}

The present study analyzed the part of the data collected from nurses working in a clinic in order to confirm the reliability and validity of the Nurse's Character Scale for Quality Care in Clinical Settings [11].

For ethical use of the data, re-analysis of the data was carried out upon approval of a public institutional review board designated by the Ministry of Health and Welfare (P01-201608-21001).

\subsection{Data analysis}

In order to measure the character of clinic nurses, the Nurse's Character Scale for Quality Care in Clinical Settings developed by Park was used [11]. This scale was developed to objectively evaluate the character characteristics that nurses working in clinical settings should possess and consisted of 2 dimensions, 13 factors, and 53 items scored on a five-point scale; high scores indicate that the nurse possesses a mature nursing character for care in clinical setting. The reliability of the scale in the pre-sent study was good, as it had a Cronbach's $\alpha=.95$.

The collected data was analyzed using IBM SPSS Version 21. The general characteristics of the participants were analyzed in real numbers and percentages. Differences in the participants' nursing character for care in clinical settings that appear according to their general characteristics were analyzed using mean scores, their standard deviations, a t-test, and a one-way ANOVA. Scheffé tests were conducted for post-hoc analysis. The maturity of the participants' nursing character for care in clinical settings was analyzed using mean and standard deviation. The level of statistical significance was set at $<.05$.

\section{Results}

\subsection{Differences in nursing character for quality care in clinical settings by general characteristics of the participants}

General characteristics of the participants of the present study were in [Table 1]. When the differences in the participants' nursing character for proper care in clinical settings were analyzed according to their general characteristics, statistically significant differences were observed in all variables except on gender and their department.

\subsection{Maturity of the participants' nursing character for quality care in clinical settings}

The mean score of the participants' nursing character for quality care in clinical settings was $3.83 \pm 0.36$. Among the 13 factors of character, the factor with the highest score was integrity, followed by reliability and etiquette, and three factors with the lowest scores were composure, enthusiasm, and civility [Table 2]. 
Table 1. Differences of character score by general characteristics of the participants $(\mathrm{N}=683)$

\begin{tabular}{|c|c|c|c|c|c|c|c|}
\hline \multirow{2}{*}{ Characteristics } & \multirow{2}{*}{ Categories } & \multirow{2}{*}{\multicolumn{2}{|c|}{$\mathrm{n}(\%)$}} & \multicolumn{4}{|c|}{ Character score } \\
\hline & & & & $\mathrm{M} \pm \mathrm{SD}$ & $\mathrm{t}$ or $\mathrm{F}$ & $p$ & Post-hoc \\
\hline \multirow{2}{*}{ Gender } & Male & 20 & (2.9) & $3.87 \pm 0.40$ & 0.56 & .574 & \\
\hline & Female & 661 & $(97.1)$ & $3.82 \pm 0.36$ & & & \\
\hline \multirow{5}{*}{ Age(year) } & $21-25^{\mathrm{a}}$ & 241 & 35.6 & $3.76 \pm 0.34$ & 21.10 & $<.001$ & $\mathrm{a}, \mathrm{b}, \mathrm{c}<\mathrm{d}, \mathrm{e}$ \\
\hline & $26-30^{\mathrm{b}}$ & 223 & 32.9 & $3.76 \pm 0.33$ & & & \\
\hline & $31-35^{\mathrm{c}}$ & 86 & 12.7 & $3.83 \pm 0.36$ & & & \\
\hline & $36-40^{\mathrm{d}}$ & 36 & 5.3 & $3.99 \pm 0.29$ & & & \\
\hline & $41 \leq^{e}$ & 91 & 13.4 & $4.10 \pm 0.35$ & & & \\
\hline \multirow{2}{*}{ Marital status } & Married & 194 & $(28.4)$ & $3.96 \pm 0.37$ & -6.39 & $<.001$ & \\
\hline & Not married & 488 & (71.6) & $3.77 \pm 0.34$ & & & \\
\hline \multirow{2}{*}{ Children } & Have & 146 & $(21.4)$ & $4.02 \pm 0.35$ & -7.50 & $<.001$ & \\
\hline & Don't have & 535 & $(78.6)$ & $3.77 \pm 0.34$ & & & \\
\hline \multirow{3}{*}{ Education } & College $^{a}$ & 246 & $(36.6)$ & $3.77 \pm 0.33$ & 14.34 & $<.001$ & $\mathrm{a}, \mathrm{b}<\mathrm{c}$ \\
\hline & University $^{\mathrm{b}}$ & 339 & $(50.4)$ & $3.82 \pm 0.35$ & & & \\
\hline & Above master ${ }^{c}$ & 87 & (12.9) & $4.00 \pm 0.40$ & & & \\
\hline \multirow{2}{*}{ Religion } & Don't have & 244 & (37.3) & $3.77 \pm 0.34$ & 2.59 & .010 & \\
\hline & Have & 411 & $(62.7)$ & $3.85 \pm 0.36$ & & & \\
\hline \multirow{3}{*}{ Position } & Nurse $^{a}$ & 570 & $(83.8)$ & $3.79 \pm 0.35$ & 24.85 & $<.001$ & $\mathrm{a}<\mathrm{b}<\mathrm{c}$ \\
\hline & Charge nurse ${ }^{b}$ & 69 & $(10.1)$ & $3.95 \pm 0.32$ & & & \\
\hline & Above head nurse & 41 & (6.0) & $4.14 \pm 0.31$ & & & \\
\hline \multirow{2}{*}{ Department } & Ward & 502 & (74.0) & $3.82 \pm 0.35$ & -1.27 & .204 & \\
\hline & Others & 176 & (26.0) & $3.86 \pm 0.37$ & & & \\
\hline \multirow{4}{*}{$\begin{array}{c}\text { Duration of } \\
\text { working(year) }\end{array}$} & $\leq 1^{\mathrm{a}}$ & 58 & $(8.8)$ & $3.74 \pm 0.36$ & 21.33 & $<.001$ & $a, b, c<d$ \\
\hline & $1<, \leq 5^{b}$ & 274 & $(41.4)$ & $3.76 \pm 0.34$ & & & \\
\hline & $5<, \leq 10^{c}$ & 174 & (26.3) & $3.80 \pm 0.33$ & & & \\
\hline & $10<\mathrm{d}$ & 156 & $(23.6)$ & $4.02 \pm 0.36$ & & & \\
\hline
\end{tabular}

\section{Discussion}

The present study was a descriptive study that aimed to determine the directions, subjects, and contents of character education programs required in nursing by investigating the differences and maturity of nurses' character for quality care in clinical settings according to the general characteristics of nurses currently working in clinic. The results of the present study showed that the overall score indicating the character maturity of nurses in clinic was above intermediate, at $3.83 \pm 0.36$ out of 5 . Out of the 13 factors of character, integrity, credibility, etiquette, and diligence had the highest scores, while composure, enthusiasm, and civility had the lowest scores. In particular, the participants scored low on these three factors with the lowest scores regardless of their education, position, and duration of working. Moreover, it was found that on the teamwork factor there were significant differences in the 
groups of nurses, showing significantly lower scores in general nurses, nurses with college or university degrees, and nurses that have worked for less than 10 years.

Table 2. Character's characteristics of the participants $(\mathrm{N}=683)$

\begin{tabular}{|c|c|c|c|c|c|c|c|c|c|}
\hline \multirow{2}{*}{\multicolumn{2}{|c|}{ Character's Characteristics }} & \multirow{3}{*}{$\begin{array}{l}\mathrm{M} \pm \mathrm{SD} \\
3.94 \pm 0.49\end{array}$} & \multicolumn{2}{|l|}{ Education } & \multicolumn{3}{|l|}{ Position } & \multicolumn{2}{|c|}{ Duration of working } \\
\hline & & & \multirow{2}{*}{$\begin{array}{l}\text { <master } \\
3.90 \pm 0.48\end{array}$} & \multirow{2}{*}{$\begin{array}{l}\text { master } \leq \\
4.15 \pm 0.52\end{array}$} & \multirow{2}{*}{$\begin{array}{l}\text { Nurse } \\
3.88 \pm 0.48 \\
\end{array}$} & \multirow{2}{*}{$\begin{array}{l}\text { Charge nurse } \\
4.18 \pm 0.45 \\
\end{array}$} & \multirow{2}{*}{$\begin{array}{l}\text { Head nurse } \leq \\
4.29 \pm 0.45\end{array}$} & \multirow{2}{*}{$\begin{array}{l}\leq 10 \\
3.85 \pm 0.47\end{array}$} & \multirow{2}{*}{$\begin{array}{l}10< \\
4.21 \pm 0.47\end{array}$} \\
\hline & Responsibility & & & & & & & & \\
\hline dime & Enthusiasm & $3.43 \pm 0.49$ & $3.38 \pm 0.46$ & $3.78 \pm 0.53$ & $3.37 \pm 0.47$ & $3.66 \pm 0.50$ & $3.84 \pm 0.49$ & $3.34 \pm 0.46$ & $3.72 \pm 0.49$ \\
\hline & Industriousness & $3.99 \pm 0.58$ & $4.00 \pm 0.57$ & $4.14 \pm 0.58$ & $3.95 \pm 0.57$ & $4.10 \pm 0.55$ & $4.40 \pm 0.57$ & $3.91 \pm 0.57$ & $4.24 \pm 0.53$ \\
\hline & Composure & $3.35 \pm 0.55$ & $3.32 \pm 0.54$ & $3.52 \pm 0.57$ & $3.32 \pm 0.55$ & $3.47 \pm 0.51$ & $3.56 \pm 0.53$ & $3.31 \pm 0.54$ & $3.51 \pm 0.56$ \\
\hline \multirow{9}{*}{$\begin{array}{l}\text { Interpersonal } \\
\text { dimension }\end{array}$} & Integrity & $4.13 \pm 0.43$ & $4.12 \pm 0.43$ & $4.23 \pm 0.45$ & $4.12 \pm 0.44$ & $4.16 \pm 0.41$ & $4.27 \pm 0.38$ & $4.12 \pm 0.44$ & $4.20 \pm 0.41$ \\
\hline & Reliability & $4.11 \pm 0.60$ & $4.07 \pm 0.60$ & $4.35 \pm 0.56$ & $4.05 \pm 0.59$ & $4.36 \pm 0.52$ & $4.50 \pm 0.56$ & $4.02 \pm 0.58$ & $4.40 \pm 0.59$ \\
\hline & Kindness & $3.82 \pm 0.50$ & $3.81 \pm 0.50$ & $3.89 \pm 0.52$ & $3.80 \pm 0.51$ & $3.81 \pm 0.47$ & $4.04 \pm 0.43$ & $3.78 \pm 0.50$ & $3.92 \pm 0.48$ \\
\hline & Listening & $3.77 \pm 0.50$ & $3.75 \pm 0.49$ & $3.93 \pm 0.51$ & $3.74 \pm 0.50$ & $3.85 \pm 0.43$ & $4.07 \pm 0.51$ & $3.72 \pm 0.50$ & $3.93 \pm 0.47$ \\
\hline & Empathy & $3.91 \pm 0.52$ & $3.89 \pm 0.51$ & $4.05 \pm 0.56$ & $3.89 \pm 0.53$ & $4.01 \pm 0.49$ & $4.08 \pm 0.38$ & $3.88 \pm 0.54$ & $4.02 \pm 0.47$ \\
\hline & Teamwork & $3.67 \pm 0.52$ & $3.61 \pm 0.50$ & $4.02 \pm 0.54$ & $3.58 \pm 0.49$ & $3.97 \pm 0.47$ & $4.27 \pm 0.47$ & $3.56 \pm 0.48$ & $4.03 \pm 0.50$ \\
\hline & Civility & $3.62 \pm 0.52$ & $3.59 \pm 0.52$ & $3.78 \pm 0.50$ & $3.58 \pm 0.53$ & $3.68 \pm 0.44$ & $4.01 \pm 0.46$ & $3.57 \pm 0.51$ & $3.77 \pm 0.54$ \\
\hline & Etiquette & $4.11 \pm 0.55$ & $4.01 \pm 0.54$ & $4.31 \pm 0.62$ & $4.08 \pm 0.56$ & $4.18 \pm 0.51$ & $4.38 \pm 0.50$ & $4.06 \pm 0.55$ & $4.28 \pm 0.53$ \\
\hline & Interactional justice & $3.90 \pm 0.60$ & $3.90 \pm 0.59$ & $3.90 \pm 0.61$ & $3.89 \pm 0.60$ & $3.91 \pm 0.61$ & $4.13 \pm 0.55$ & $3.88 \pm 0.60$ & $3.99 \pm 0.60$ \\
\hline \multicolumn{2}{|l|}{ Total } & $3.83 \pm 0.36$ & $3.80 \pm 0.34$ & $4.00 \pm 0.40$ & $3.79 \pm 0.35$ & $3.95 \pm 0.32$ & $4.14 \pm 0.31$ & $3.77 \pm 0.34$ & $4.02 \pm 0.36$ \\
\hline
\end{tabular}

These findings indicate the need to implement the nursing character education programs in nursing education and in clinical settings, and have the following significant implications. First, it is necessary to introduce systematic nursing character education programs to university nursing curricula. Character education in South Korea generally emphasizes education during early life, focusing mostly on toddlers, preschoolers, and elementary school students. However, companies strongly require good character from university graduates, even more than other capabilities [4], and medical institutions are not an exception. In a study by Seong and Kim [12], which investigated the awareness of the importance of character education and maturity in university students enrolled in 19 departments, nursing students had a low awareness of the importance of character education, and their character maturity was not significantly higher when compared to students enrolled in other departments in health sciences. Therefore, it is necessary to provide opportunities in character education through university nursing programs so that students can develop the relevant characteristics required for nurses and the importance, of cultivating their character as competent nurses. Our results show that the character maturity of nurses currently working in clinic is above intermediate. However, as Nightingale [13] also emphasized, because nurses work is centered on humans, and they should possess a more matured character. Therefore, education to cultivate character is necessary in nursing education.

Second, internal education or supplementary educations are required at medical institutions in order for character education to continue in clinics. According to our findings, nurses currently working in clinic possess honesty or integrity, which has been emphasized the most in nursing [13][14][15] in other words, they are carrying out their tasks with a sense of responsibility and sincerity. However, the present study found that charge and head nurses that have worked for more than 10 years are not an exception to this, and needed to improve certain aspects of their character. It suggested that, general nurses that have worked for less than 10 years should work on improving their composure. Where composure is required to 
cope with various clinical situations with a calmness in mind; civility, which refers to attitudes and behaviors that respect others' personality; enthusiasm, which is required to improve one's professional skills and to improve tasks; and teamwork, which is required in helping colleagues to carry out the team's tasks smoothly. These four factors should be included in clinical character education.

According to the study of Lee [10], sufficient professional knowledge is one of the five factors that failed to meet hospitalized patients' expectations. Enthusiasm is a factor of character that is required to increase one's expertise, which comprises knowledge and experiences in one's field of expertise. Expertise is a basic element required for a professional, and is a characteristic required for a good nurse [8]. Nurses acquire various clinical experiences while facing unexpected situations, ethical dilemmas, and new treatment and nursing methods in clinics. Nurses should aim to cultivate and develop themselves as professionals through continuous research and efforts based on these experiences.

In the present study, nurses working in clinic self-evaluated their own character using the Nurse's Character Scale for Care in Clinical Settings. Therefore, a limitation of the present study is that the participants could have over or underestimated their own behaviors and attitudes.

\section{Conclusions}

The present study found that nursing character education programs arguably ought to contain the 13 factors of nursing character for care in clinical settings, with a particular focus on achieving step-wise improvements in composure, civility, enthusiasm, and teamwork. The author suggests continuous research on the development and application of nursing character education programs and on effective education methods for said programs.

\section{Acknowledgements}

This work was supported by Gyeongnam National University of Science and Technology Grant in 2016.

\section{References}

[1] The National Institute of the Korean Language, http://stdweb2.korean.go.kr/main.jsp, (2016)

[2] J. H. Son, "Exploration into factors influencing female college students' career decision process: Focusing in academically talented high-school graduates," The Korean Journal of Counselling and Psychotherapy, vol.22, no.2, pp.435-457, (2010)

[3] Y. O. Yang and S. O. Lee, "The relations of self-esteem, major satisfaction and career identify on the nursing students," Journal of the Korean Data Analysis Society, vol.14, no.2, pp.979-989, (2012)

[4] S. S. Yang, H. J. Kim, and K. P. Joo, "A study of companies' perception on university education and their needs," Korea Research Institute for Vocational Education \& Training, vol.80, no.1, pp.319-337, (2006)

[5] J. H. Park, "Need of character education in nursing education," Journal of the Korean Data Analysis Society, vol.15, no.6, pp.3321-333, (2013)

[6] M. Brady, "Hospitalized children's views of the good nurse," Nursing Ethics, vol.16, no.5, pp.543-560, (2009)

[7] S. S. Han, Y. R Um, Y. S. Hong, and N. O. Cho, "Korean patients' conceptions of a good nurse," Korean Journal of Medical Ethics and Education, vol.9, no.2, pp.125-142, (2006)

[8] N. O. Cho, Y. S. Hong, S. S. Han, and Y. R. Um, "Attributes perceived by cancer patients as a good nurse," Clinical Nursing Research, vol.11, no.2, pp.149-162, (2006) 
[9] J. H. Kim and I. S. Lee, "The differences in quality perceptions, expectations, evaluation, and satisfaction for nursing service between patients and nurses: Small-medium sized general hospitals," Journal of Korean Academy of Nursing, vol.34, no.7, pp.1243-1254, (2004)

[10] M. A. Lee, "A study of the nursing service quality and satisfaction that admitted patients perceived, being used SERVQUAL," Journal of Korean Academy of Nursing, vol.32, no.4, pp.506-518, (2002)

[11] J. H. Park, "Development and validation of nurse's character scale for care in clinical settings," Journal of the Korean Academic Society of Nursing Education, vol.22, no.2, pp.137-151, (2016)

[12] M. H. Seong and E. J. Kim: “An analysis on college students' awareness of the importance of personality education, personality development level and their demand for personality education," Journal of Korea Ethics Education, vol.38, no.1, pp.177-202, (2015)

[13] F. Nightingale, "Notes on nursing: what it is and it is not," New York: D. Appleton and Company, pp.12439, (1860)

[14] J. Franks, "The caring character," Nursing Standard, vol.23, no.26, pp.61, (2009)

[15] Nursing and Midwifery Council, "Guidance on professional conduct for nursing and midwifery students 3rd ed," http://www.cmft.nhs.uk/media/288385/ student\%20conduct\%202011\%20code.pdf, (2011) 